\title{
Girdi Çıktı Analizi ile Yeni Ekonomi Programı Hedeflerinin Değerlendirilmesi
}

\author{
Ahmet SEL \\ Millî Eğitim Bakanlığ1 \\ selahmet43@gmail.com \\ ORCID ID: 0000-0003-1914-5878 \\ Hüdaverdi BİRCAN \\ Sivas Cumhuriyet Üniversitesi \\ hbircan@cumhuriyet.edu.tr \\ ORCID ID: 0000-0002-1868-1161
}

\begin{tabular}{lrr} 
Araştırma Makalesi & DOI: $10.31592 /$ aeusbed.727266 \\
\hline Geliş Tarihi: 26.04 .2020 & Revize Tarihi:21.09.2020 & Kabul Tarihi: 15.10 .2020
\end{tabular}

\section{Atıf Bilgisi}

Sel, A. ve Bircan, H. (2020). Girdi çıktı analizi ile yeni ekonomi programı hedeflerinin değerlendirilmesi. Ahi Evran Üniversitesi Sosyal Bilimler Enstitüsü Dergisi, 6(3), 746-759.

\section{ÖZ}

Girdi çıktı tabloları bir ekonomide bulunan sektörlerin arz talep ilişkisi içerisinde birbirleriyle olan ekonomik etkileşimlerini gösterir. Türkiye ekonomisi için Türkiye İstatistik Kurumu tarafından en son hazırlanan girdi çıktı tablosu 64 sektörlü ve 2012 yılına aittir. Girdi çıktı tablosuyla yapılan analiz sonuçlarının daha anlamlı ve yorumlanabilir olması adına Ekonomik Faaliyetlerin İstatistiksel Sınıflandırmas1 (NACE) Rev-2 ekonomik sınıflaması kullanılarak tablo toplulaştırma işlemiyle 27 sektöre indirgenmiștir. 2012 yılı girdi çıktı tablosu RAS yöntemi kullanılarak önce 2014 yılına, 2014 yılı tablosu kullanılarak da 2016 yılına güncellenmiştir. Çalışmada girdi çıktı tabloları yardımıyla Türkiye ekonomisinin var olan hedeflerinin yorumlanması adına hedef programlama modelleri kurulmuştur. Hedefler için Kalkınma Bakanlığı tarafından Yeni Ekonomi Programı ele alınmıştır. Programda belirlenen Gayri Safi Yurtiçi Hasıla ve istihdam hedefleri eşit öncelikli tutularak gereken sektörel üretim değerleri aranmıştır. Yeni Ekonomi Programı için 2016 yılı baz alınırsa 2019, 2020 ve 2021 yılları için ortalama toplam Gayri Safi Yurtiçi Hasıla'da \%32,61 ve toplam arzda \%22,48 artış olması gerektiği belirlenmiştir. Yeni Ekonomi Programı hedeflerine ulaşılmasında sektörel olarak Sektör-1:Tarım, Sektör-2:Maden ve Sektör-14:Elektrik ve iklimlendime sektörlerinin katkılarının daha fazla olduğu görülmüştür. Elde edilen sonuçların karar vericilere yatırımların yönlendirimesi konusunda katkı sağlaması beklenmektedir.

Anahtar Kelimeler: Girdi çıktı analizi, yeni ekonomi programı, hedef programlama.

\section{Evaluation of New Economy Program Objectives by Input Output Analysis}

\begin{abstract}
Input-output tables show the economic interactions of the sectors in an economy with each other in the supply-demand relationship. The latest input-output tables prepared by the Statistical Institute of Turkey for Turkey's economy belongs to the sector and 64 in 2012. In order to make the analysis results made with the input-output table more meaningful and interpretable, the table was reduced to 27 sectors by using the Statistical Classification of Economic Activities in the European Community (NACE) Rev-2 economic classification. The 2012 input-output table was first updated to 2014 using the RAS method and to 2016 using the 2014 table. for the interpretation of the existing target of input-output tables with the help of Turkey's economy it has been established in the study target programming models. The New Economy Program was addressed by the Ministry of Development for the Goals. The gross domestic product and employment targets determined in the program were kept at the same priority and required sectoral production values were sought. Based on 2016 for the New Economy Program, it is determined that there should be an increase of $32.61 \%$ in average total Gross Domestic Product and 22.48\% in total supply for 2019, 2020 and 2021. It has been observed that the contribution of the Sector-1: Agriculture, Sector-2: Mining and Sector-14: Electricity and air-conditioning sectors is more sectoral in reaching the new economy program targets. The results obtained are expected to contribute to decision makers in directing investments.
\end{abstract}

Keywords: Input output analysis, new economy program, goal programming.

\section{Giriş}

Girdi çıktı modelleri ilk olarak Amerika ekonomisinin yapısal analizini inceleyen Prof. Wassily W. Leontief tarafından 1930 yıllarda oluşturulmuştur. Bu çalışmasında kapalı modeller üzerinde duran Prof. Wassily W. Leontief 1951 yılında statik ve açık modelleri yayınlayarak uygulama alanını genişletmiştir. Belli bir yıla ait ekonomik verilerin incelenmesiyle elde edilen girdi 
çıktı modelleri sektörel bağlantı etkileri, kilit sektörler ve çoğaltan analizleri yardımıyla uygulamada daha etkin bir yer bulmuştur.

\begin{abstract}
"Bölgesel iktisadi analizin önemli bir aracını oluşturan girdi-çıktı modelleri, ekonominin hem bir bütün olarak hem de sektör (endüstri) düzeyinde incelenmesine olanak sağlayan, matematiksel yapısı basit ve uygulamada sık kullanılan modellerdir. Girdi-çıktı tablosu belli bir yılda bir ulusal ekonominin veya bölgenin ekonomisinin sektörleri arasında her türlü alışverişi yansıtan simetrik tablolardır. Bir girdi-çıktı tablosunda her sektörün kendi üretimini gerçekleştirmek için kullandığı ara girdilere ve emek ve sermaye gibi üretim faktörlerine yaptığı ödemeler ile, her bir sektörde üretilen mal veya hizmetin nerelerde kullanıldığı (diğer sektörler tarafından üretimde aramal olarak, tüketim amacıyla, yatırım amacıyla, ihracat, vs.) açık olarak yer alır” (Aydoğuş, 2012, s. 11).
\end{abstract}

Ülkeler planlı ve programlı olması adına ekonomik gelişmelerini belirli bir yol haritasında yürütmektedirler. Belirli aralıklarla yayınlanan ekonomi programları sayesinde bu yol haritası çizilir. Programların içeriğinde kısa, orta ve uzun vade ekonomik veriler bulunduğu gibi sosyo-kültürel gelişmelerde yer almaktadır. Böylelikle toplumu her yönüyle ilgilendiren bir plan otoritelerce halka açılanmış olur.

"Gelişme yolundaki ülkelerin kalkınma amaçlarına paralel olarak uyguladıkları politikalar ekonomik yapı değişimini sağlayacak şekilde olmalıdır. Türkiye’nin sanayileşme olgusuyla birlikte hızlı bir yapısal değişime girdiği de bir gerçektir. Geniş bir ekonomik yapı kavramına bağlı olarak ekonomide ki yapısal değişimi açıklamaya yönelik yaklaşımlar ilginç sonuçlar çıkarabilmektedir. Bu yaklaşımlardan girdi-çıktı modeli geniş bir kabul ve önemli bir rol almıştır. Girdi-çıktı modeli gerek endüstriler arası yapı gerekse bu yapı ve model dişı kalan ekonomik mekanizma unsurlarının ilişkilerini (bağıntılarını) açıklamada ki başarısı ile geniş bir uygulama alanı bulmaktadır” (Karkacıer, 2001, s. 1).

"Girdi çıkt1 modelleri doğrusal programlama modelinin özel bir hali olarak söylenebilir. Özellikle etkinlik planlamasında girdi çıktı modelleri birer optimizasyon modeli olarak ifade edilebilir" (Aydoğuş, 2010, s. 6). Doğrusal programlama çerçevesinde maksimizasyon ve minimizasyon modelleri kurulabileceği gibi belirlenen hedefler çerçevesinde de doğrusal programlama modelleri tasarlanabilir.

Girdi çıktı modellerinin doğrusal programlama ile kullanıldığ çalışmalar incelendiğinde; Dalkılıç (1999), girdi çıktı analizi ile birlikte kullanılan doğrusal programlama yerine çok ölçütlü karar verme tekniklerinden biri olan Hedef Programlama kullanarak iki farklı amaç çerçevesinde bir kalkınma planı oluşturulmuştur. Türkiye İstatistik Kurumu (TÜIK) tarafından hazırlanan 64 sektörlü 1990 girdi çıktı tablosu toplulaştırma işlemiyle 9 sektöre indirgenmiştir. Çözüm aşamasında ise temel ekonomik göstergeler ve işgücü anketlerinden faydalanılmıştır. Doğrusal proglamlama ile girdi çıktı tablosunun kullanılmasında Can ve Özlüer (2012), TÜİK tarafından hazırlanan 2002 toplulaştırılmış girdi çıktı tablosu ile iktisadi planlama sürecinde sektörel üretim düzeylerini saptamak ve buna göre yatırımların sektörel dağılımını belirlemek için üretim faktörleri analiz edilmiştir. Üretim faktörleri girdi çıktı tablosu üzerinden belirlenerek mevcut kaynaklar dahilinde verimli bir şekilde dağıtılması istenmiştir. Girdi çıtı tablosu 6 sektöre indirgenerek amaç olarak milli geliri yani faktörlere yapılan ödemelerin katma değer olarak maksimum olması istenmiştir. Ekonomideki kullanılabilir sermaye, işgücü ve arz-talep dengesi kısıt olarak eklenmiştir.

Girdi çıktı tabloları ekonomik alanda kullanılması rağmen günlük hayata yansımaları oldukça fazladır. Kondo ve Nakamura (2005), çalışmalarında doğrusal programlama yöntemi kullanarak atıklar üzerinden oluşturulan girdi çıktı modelinin değerlendirilmesini yapmıştır. Atık girdi çıktı doğrusal programlama modeli olarak adlandırılan sonuç modelinde verilen alternatif uygulanabilir strateji kümesinden otomatik olarak bir "optimal" atık yönetimi ve geri dönüşüm stratejisi elde edilmesi istenmiştir. Böylece model, belirli bir eko-verimlilik ölçüsünün mevcut (teknolojik ve kaynak) potansiyellerin uygun bir kombinasyonu ile ne kadar arttırılabileceğini belirlemiştir. Japonca verilerine bir uygulama da sunulmuştur. Ayrıca Konstantinos (2005), çalışmasında bir kamu ormanında yıldan yıla meydana gelen çoklu kullanım yönetimi planlaması sorununa hedef programlama ve ürün girişi analizi şeklinde makul bir çözüm aramıştır. Çalışmanın uygulanabilirliğini kolaylaştırmak için, ilk 
önce doğrusal programlama biçiminde girdi çıktı analizi ile birlikte bir orman yönetimi sorunu ortaya konmuştur. Sorun daha sonra bir hedef programlama formatına dönüştürülerek çözümlenmiştir. Çevresel etkileri konusunda Ribeiro, Kênia ve Fernando (2016), çalışmalarında Brezilya üzerinde sera gazı emisyonlarının neden olduğu etkileri ekonomik ve çevresel açıdan değerlendirmişlerdir. Bu doğrultuda hükümetin tüm Brezilya sera gazı emisyonlarının \%5'ini azaltan bir iklim politikası benimsemeye karar verirse, ekonomik etkinin ne olacağına dair simülasyon yapılmıştır. Bunun için 2009 yılında Brezilya girdi-çıktı matrisini ve Bilim, Teknoloji ve Yenilik Bakanlığı'ndan gelen emisyon verileri kullanılmıştır. Çözümlemelerde girdi çıktı tablosu ile doğrusal programlama bir arada kullanılmıştır. Genel olarak, sera gazı emisyonlarının azaltılmasının her \%1'i için toplam çıktıda en az $\% 0,06$ oranında bir azalmaya yol açtığı görülmüştür. Ekonomik kalkınma konusunda Oliveira, Coelho ve Antunes (2014), çalışmalarında bilimsel literatürdeki girdi çıktı analizinin çoklu hedef modellerle birleştirilmesine dayanan farklı modelleme yaklaşımları kullanmışlardır. Politika yapıcılar için mevcut durgun ekonomik bağlamda ekonomik kalkınmanın ekonomi-enerji çevresi ile sürdürülebilir kalkınmanın sosyal direkleri arasındaki değişimleri değerlendirmenin yararlı olabileceğini öne sürmüşlerdir. Ayrıca, girdi çıktı analizinin mikroekonomiden makroekonomiye, karmaşı ekonomik ve fiziksel ilişki sistemlerinin modellenmesinde kullanılabilecek çok çeşitli sorunların teorik veya ampirik çalışmaları için esnek bir araç olduğu belirtilmiştir. Girdi çıktı analizi için güvenilir ekonomik veriler kullanıldığında ekonomik sektörlerin üretimindeki değişikliklerin neden olduğu her türlü çevresel yükün değerlendirilmesini sağladığı belirtilmiştir. Yu, Aviso ve Santos (2016), çalışmalarında kıt mal veya kaynakların tahsis edilmesinin optimize edilebileceği bir doğrusal programlama modeli ile iklimsel bozulmaların neden olduğu kıtlık koşulları altında, bulanık ekonomik çıktı hedeflerinin genel değerlendirmesini yapmışlardır. Önerilen model, Filipin ekonomisinde kuraklığa bağlı elektrik sıkıntısı senaryosuna dayalı bir vaka durumu ele almıştır. Sonuçları ise ticaret, nakliye ve hizmet odaklı endüstrilerin böyle bir durumda gayri safi yurtiçi hasılada zarar gördügünü göstermektedir.

Türkiye'de Kalkınma Bakanlığı tarafından ilan edilen programlar vasıtasıyla belirlenen ekonomik hedefler kamuoyu ile paylaşılmaktadır. Bu çalışmada Yeni Ekonomi Programı (YEP) içerisindeki hedefler girdi çıktı tabloları ile incelenmiştir. Programda belirlenen Gayri Safi Yurtiçi Hasıla (GSYH) ve istihdam hedefleri dikkate alınarak çözümlemeler olan sektörel üretimler hesaplanmıştır. YEP dikkate alınarak 2019, 2020 ve 2021 yılları için GSYH ve istihdam hedefleri incelenmiş ve 2016 girdi çıktı tablosu ile hedef programlama yardımıyla bu hedefler değerlendirilmiştir. Çalışma sonuçlarının güncel ve uygulanabilir olması adına en son yayınlanan girdi çıktı tablosu kullanılmış ve 64 sektörlü 2012 girdi çıktı tablosu toplulaştırma işlemi yardımıyla 27 sektöre indirgenmiştir. Daha sonra 2012 yılına ait olan girdi çıktı tablosu RAS yöntemiyle 2014, 2014 güncel tablosuyla da 2016 yılına güncellenmiştir.

\section{Yöntem}

Girdi çıktı tabloları optimizasyon işlemlerinde etkin olarak kullanabilen modellerdir. Doğrusal ve hedef programlama çalışmalarında girdi çıktı tablosunun oluşturulduğu ilgili ekonominin kısıtlar çerçevesinde değerlendirimesi yapılabilir.

\footnotetext{
"Hedef programlama modeli, doğrusal programlama modeli gibi kısıtlayıcı kümesi ve amaç fonksiyonu şeklinde iki bölümde incelenebilir. Bir doğrusal programlama modelinde yer alan bütün fonksiyonlar hedef programlama modelinin sadece kısıtlayıcı kümesini oluşturur. Hedef programlama modelinde, amaç fonksiyonları için ulaşılmak istenen erişim değerlerini karar vericinin belirlemesi gerekir. Bunun doğal bir sonucu olarak, erişim değerli amaç fonksiyonları bir eşitlik halinde kısıtlayıcı kümesine eklenir. $\mathrm{Bu}$ işlem her bir hedef fonksiyonu için sapma değişkenlerinin tanımlanmasını gerektirir. Sapma değişkenleri, hedef fonksiyonlarının erişim düzeylerinden ne kadar uzaklaşsı̆̆ının ölçülmesini sağlar. Hedef programlama modelinde, hedefler için belirlenen erişim düzeylerinden oluşabilecek sapmalar minimize edilir" (Özkan, 2003, s. 175).
}

YEP yayınlanan işgücü ve istihdam hedefleri için girdi çıtı tabloları ile bu hedeflerin gerçekleşmesi için gereken sektörel üretim değerleri araştırılmıştır. Hedef programlama modelinde bir hedef üzerine çalışmalar yapılabileceği gibi birden fazla hedef çerçevesinde de işlemler yapılabilir. 
Ekonominin temel dinamiklerinin incelendiği GSYH hedefi " $\mathrm{Z}_{\mathrm{GSYH}}$ " ve istihdam hedefi "Ziş" olarak tanımlandığında arz-talep, sabit sermaye kullanımı ve işgücü kısıtları altında hedeften sapmaları minimum yapan değerler için model Eşitlik 1 gibi düzenlenebilir.

$$
\begin{aligned}
& \min =d_{1}^{-}+d_{1}^{+}+d_{2}^{-}+d_{2}^{+} \\
& Z_{i s}=\sum_{j=1}^{n} l_{j} X_{j}+d_{1}^{-}-d_{1}^{+} \\
& Z_{G S Y H}=\sum_{j=1}^{n} g_{j} X_{j}+d_{2}^{-}-d_{2}^{+} \\
& \sum_{j=1}^{n}\left(1-a_{i j}\right) X_{j} \geq Y_{i} \\
& \sum_{j=1}^{n} l_{j} X_{j} \geq L \\
& \sum_{j=1}^{n} k_{j} X_{j} \leq K \\
& X_{j} \geq 0
\end{aligned}
$$

Eşitlik 1'de yer alan ifadelerin açıklamaları aşağıdaki gibidir.

$X_{j}$ : j sektöründeki üretim düzeyi

$a_{i j}$ : j sektörünün bir birim mal üretebilmek için gereksinim duyduğu i malı miktarı

$Y_{i}$ : i sektörünün toplam nihai tüketim harcamas1

$l_{j}$ : j sektörünün bir birim mal üretebilmek için ihtiyacı olan işgücü miktarı

$g_{j}$ : j sektörünün bir birim mal üretebilmek için ihtiyacı olan GSYH miktarı

$L$ : ekonomideki mevcut işgücü miktarı

$k_{j}$ : j sektörünün bir birim mal üretebilmesi için gerekli olan sermaye miktarı

$K$ : ekonomideki kullanılabilir sermaye miktarı

$d_{l^{-}}{ }^{-}$istihdam hedefi için negatif yönlü sapma değeri

$\mathrm{d}_{l}^{+}$: istihdam hedefi için pozitif yönlü sapma değeri

$d_{2}^{-}$: GSYH hedefi için negatif yönlü sapma değeri

$d_{2}{ }^{+}:$GSYH hedefi için pozitif yönlü sapma değeri

Uygulamalar sırasında hedefler için herhangi bir öncelik belirlenmemiştir. GSYH ve istihdam hedefleri eşit önemde yani katsayıları eşit olarak değerlendirilerek çözümler aranmıştır. Hedeflerin gerçekleşmesi için sektörel üretim tutarları olan " $X_{j}$ ” değerleri elde edilen çözümlerdir.

\section{Veri Seti ve Kullanılan Değişkenler}

Çalışmada kullanılan verilerin tamamı TÜiKK ve kamu kurumları tarafından açık erişimli yayınlanan verilerden oluşmaktadır. 64 sektörlü 2012 girdi çıktı tablosu TÜIKK tarafından güncel olarak kullanılan NACE Rev-2 ekonomik sınıflaması dikkate alınarak 27 sektöre toplulaştırılmıştır. Toplulaştırma işlemi sonucunda oluşan sektörler ve daha sonra tablolarda kullanılacak kodlamaları Tablo 1'deki gibidir. 
Tablo 1

NACE REV-2 ile Toplulaştırılmış Sektörler Tablosu

\begin{tabular}{llllll}
\hline Sektör Kodu & NACE Kodu & Sektör Kodu & NACE Kodu & Sektör Kodu & NACE Kodu \\
\hline S-1 & A & S-10 & C26-C27 & S-19 & I \\
S-2 & B & S-11 & C28-C33 & S-20 & J \\
S-3 & C10-C12 & S-12 & C29-C30 & S-21 & K \\
S-4 & C13-C15 & S-13 & C31-C32 & S-22 & L \\
S-5 & C16-C17-C18 & S-14 & D & S-23 & M \\
S-6 & C19 & S-15 & E & S-24 & N-O \\
S-7 & C20-C21 & S-16 & F & S-25 & P \\
S-8 & C22-C23 & S-17 & G & S-26 & Q-S-T \\
S-9 & C24-C25 & S-18 & H & S-27 & R \\
\hline
\end{tabular}

Girdi çıktı tablolarının hazırlanması gerçekten fazlasıyla emek ve zaman isteyen bir uygulamadır. Türkiye'de tabloların hazırlanması ve yayınlanması TÜíK tarafından sağlanmaktadır. En son yayınlanan girdi çıktı tablosu 2016 yılının sonunda olup 2012 yılının ekonomik verilerini içermektedir. Çalışma sonuçlarının güncel ve uygulanabilir olması adına 2012 girdi çıktı tablosu ile RAS yöntemi zincirleme olarak uygulanmış 2014 ve 2016 yıllarına ait tablolar elde edilmiştir. Güncelleme işleminde ilgili yıllara ait aşağıdaki tablolar kullanılmıştır.

- TÜIK 2012 ulusal girdi-çıktı tablosu

- TÜIKK üretim yoluyla GSYH

- TÜIK harcamalar yoluyla GSYH

- TÜIK gelir yöntemiyle GSYH

- TÜIK hanehalkı bütçe anketi veri seti

- TÜİK iş ve hizmet istatistikleri

- Maliye Bakanlığı bütçe istatistikleri

- TÜIKK sektörel ithalat ve ihracat verileri

- Türkiye Cumhuriyeti Merkez Bankası (TCMB) ödemeler dengesi hizmet ticareti istatistikleri

- Sosyal Güvenlik Kurumu (SGK) kayıtlı işgücü verileri

RAS yönteminin ana hedefi, bu tabloları güncellerken, girdi ve çıktı sütunlarını veya satırlarını dengelemektir. Temel denklemler döngüsü tabloda yer alan boşluk seviyesine bağlıdır. Bu denklemler aşağıdaki gibi tanımlanır (Trinh ve Phong, 2013);

$$
X_{C}^{y}\left(t_{n}\right) \cdot X_{C}^{y}\left(t_{n-1}\right) \ldots . X_{C}^{y}\left(t_{1}\right) \cdot A \cdot X_{R}^{y}\left(t_{1}\right) \ldots . X_{R}^{y}\left(t_{n-1}\right) \cdot X_{R}^{y}\left(t_{n}\right)
$$

Eşitlik 2' de yer alan tanımlar ise:

$X_{C}^{y}\left(t_{n}\right)$ : vektörü sütunun ${ }^{t_{\bar{i}}}$ kez iterasyonu sonucu oluşan yeni çıktı değeri,

$A$ : doğrudan girdi katsayı matrisi,

$X_{R}^{y}\left(t_{n}\right)$ : vektörü satırın ${ }^{t_{\bar{i}}}$ kez iteresyonu sonucu oluşan yeni çıktı değeridir.

\section{Verilerin Analizi}

Uygulama sırasında RAS yöntemi için Pyio2.1 programı ile hedef programlama çözümlerinde Excel Solver, Matlab ve Winqsb programları kullanılmıştır. YEP içinde verilen hedef yılları 20192020 ve 2021 yıllarını kapsamaktadır. Girdi çıktı tabloları için oluşturulan son güncel tablo 2016 yılına aittir. Bu tablo dikkate alınarak YEP yer alan GSYH ve istihdam hedeflerini gerçekleştirecek üretim değerleri hesaplanmıştır. İstihdam hedefleri için çalışmanın yapıldığ 1 yılda en son yayınlanan TÜİK verisi 2017 yılındadır. Burada istihdam ödemesi 28.189 (bin) kişi için 947.078.813 (bin) TL'dir. 
2019-2020-2021 yıllarına ait olan ödeme miktarları ise hedef olarak belirlenmiştir. Ayrıca diğer hedef olan GSYH için YEP'da yer alan değerleri Tablo 2'de gösterilmiştir.

Tablo 2

Beklenen GSYH ve İsgü̈cü Ödeme Tutarlarl (Bin Kişi/Bin TL)

\begin{tabular}{llllll}
\hline Y11 & 2017 & 2018 & 2019 & 2020 & 2021 \\
\hline İstihdam & 28.189 & 28.677 & 29.116 & 29.877 & 30.952 \\
Ödeme & 947.078 .813 & 963.474 .373 & 978.223 .659 & 1.003 .791 .326 & 1.039 .908 .596 \\
GSYH & 3.106 .536 .751 & 3.740 .519 .000 & 4.450 .278 .000 & 5.149 .551 .000 & 5.742 .264 .000 \\
Artış & - & $20,41 \%$ & $18,97 \%$ & $15,71 \%$ & $11,51 \%$ \\
\hline
\end{tabular}

Çalışmada kullanılan kısıtlar Ci'ler olmak üzere C1'den C27'ye kadar olan kısıtlar Eşitlik 1'de yer alan arz talep kısıtlarıdır. 27 sektör için elde edilen $\left(1-a_{i j}\right) . X_{j} \geq Y_{i}$ arz talep kısıtlamalarının sağ tarafı olan yurtiçi tüketim $\left(Y_{i}\right)$ değerleri RAS güncelleme işlemi sonucunda bulunan 2016 girdi çıktı tablosu için Tablo 3'de verilmiştir.

Tablo 3

Sektörel Yurtiçi Tüketim Değerleri (Y $\left.Y_{i}\right),($ Bin TL)

\begin{tabular}{lllllllll}
\hline Kisitlar & & $\mathrm{Yi}$ & Kistlar & & $\mathrm{Yi}$ & Kistlar & Yi \\
\hline $\mathrm{C} 1$ & $\geq$ & 130.247 .894 & $\mathrm{C} 10$ & $\geq 94.282 .953$ & $\mathrm{C} 19$ & $\geq$ & 82.948 .883 \\
$\mathrm{C} 2$ & $\geq$ & 21.306 .129 & $\mathrm{C} 11$ & $\geq 113.875 .287$ & $\mathrm{C} 20$ & $\geq$ & 54.816 .691 \\
$\mathrm{C} 3$ & $\geq$ & 253.505 .454 & $\mathrm{C} 12$ & $\geq 141.703 .127$ & $\mathrm{C} 21$ & $\geq$ & 38.258 .284 \\
$\mathrm{C} 4$ & $\geq$ & 166.771 .381 & $\mathrm{C} 13$ & $\geq 93.506 .087$ & $\mathrm{C} 22$ & $\geq$ & 232.405 .688 \\
$\mathrm{C} 5$ & $\geq$ & 15.892 .373 & $\mathrm{C} 14$ & $\geq 29.156 .865$ & $\mathrm{C} 23$ & $\geq$ & 35.022 .672 \\
$\mathrm{C} 6$ & $\geq$ & 27.701 .017 & $\mathrm{C} 15$ & $\geq 22.834 .106$ & $\mathrm{C} 24$ & $\geq$ & 172.518 .479 \\
$\mathrm{C} 7$ & $\geq$ & 48.769 .871 & $\mathrm{C} 16$ & $\geq 375.757 .115$ & $\mathrm{C} 25$ & $\geq$ & 117.230 .251 \\
$\mathrm{C} 8$ & $\geq$ & 52.680 .929 & $\mathrm{C} 17$ & $\geq 228.014 .961$ & $\mathrm{C} 26$ & $\geq$ & 138.554 .633 \\
$\mathrm{C} 9$ & $\geq$ & 127.545 .465 & $\mathrm{C} 18$ & $\geq 205.176 .505$ & $\mathrm{C} 27$ & $\geq$ & 57.073 .007 \\
\hline
\end{tabular}

Arz talep kısıtlarının sol tarafında bulunan ve 2016 girdi çıktı tablosu üzerinden hesaplanan $\left(1-a_{i j}\right)$ değerleri Leontief matrisini temsil etmektedir.

Hedef yıllar için uygulanan kısıtlamalarda 2016 yılı girdi çıktı tablosu kullanıldığı için işgücü alt limiti ve sermaye üst limiti bu tablodan elden edilen değerlerdir. C28 kısıtı sermaye kullanım üst sınırı $(K), \mathrm{C} 28 \leq 50.363 .004$ (bin) $\mathrm{T} 1$ şeklinde belirlenmiştir. C29 kısıtı çalışanlara yapılan ödeme alt sınırı(L), C29 $\geq 840.205 .090$ (bin) Tl olarak belirlenmiştir. 2019, 2020 ve 2021 y1lları için Tablo 2'de yer alan istihdam "Ödeme" ve "GSYH" tutarları hedefler olmak üzere; hedef işgücü ödeme tutarı $\left(Z_{i s ̧}\right)$ ve hedef gayri safi yurtiçi hasıla değeri de $\left(Z_{G S Y H}\right)$ olarak tanımlanmıştır.

Eşitlik 1' de belirlenen " $Z_{i s ̧}$ " ve " $Z_{G S Y H}$ " hedeflerinde yer elan sirasıyla " $l_{j}$ " işgücü ve " $g_{j}$ " GSYH katsayıları 2016 girdi çıktı tablosundan hesaplanan değerler olmak üzere sektörel olarak dağılımları Tablo 4'de gösterilmiştir. 
Tablo 4

İşgücü “" "l lj" ve GSYH " $g_{j}$ ” Hedef Katsayıları

\begin{tabular}{lllllllll}
\hline Sektör & $l_{j}$ & $g_{j}$ & Sektör & $l_{j}$ & $g_{j}$ & Sektör & $l_{j}$ & $g_{j}$ \\
\hline S-1 & 0,0258 & 0,4281 & S-10 & 0,1000 & 0,1738 & S-19 & 0,2689 & 0,4887 \\
S-2 & 0,0434 & 0,3548 & S-11 & 0,0841 & 0,4107 & S-20 & 0,1453 & 0,5068 \\
S-3 & 0,0886 & 0,7285 & S-12 & 0,0858 & 0,3648 & S-21 & 0,2562 & 0,3082 \\
S-4 & 0,0918 & 0,6816 & S-13 & 0,0771 & 0,6824 & S-22 & 0,0143 & 0,3587 \\
S-5 & 0,0721 & 0,6858 & S-14 & 0,0318 & 0,8110 & S-23 & 0,1775 & 0,5642 \\
S-6 & 0,0481 & 0,598 & S-15 & 0,0588 & 0,6316 & S-24 & 0,6148 & 0,1337 \\
S-7 & 0,0949 & 0,1387 & S-16 & 0,1542 & 0,4398 & S-25 & 0,6577 & 0,1288 \\
S-8 & 0,0818 & 0,699 & S-17 & 0,2719 & 0,2890 & S-26 & 0,3953 & 0,4277 \\
S-9 & 0,1057 & 0,4101 & S-18 & 0,0973 & 0,5780 & S-27 & 0,1158 & 0,6285 \\
\hline
\end{tabular}

\section{Bulgular}

YEP çerçevesinde GSYH ve istihdam hedeflerini gerçekleştirecek sektörel olarak üretim değerleri $\left(X_{i j}\right)$ ve Tablo 4'te yer alan katsayılar yardımıyla hesaplanan katkıları Tablo 5, Tablo 6 ve Tablo 7'de ilgili yıllar için sırasıyla verilmiştir.

Tablo 5

2019 Hedef Programlama Sektörel Üretim, GSYH ve İsgücü Ödeme Değerleri (Milyon TL)

\begin{tabular}{llllllll}
\hline Sektör & Üretim & GSYH & İşücü & Sektör & Üretim & GSYH & İşgücü \\
\hline S-1 & 1.666 .479 & 713.445 & 43.074 & S-17 & 490.631 & 141.786 & 133.410 \\
S-2 & 317.073 & 112.494 & 13.753 & S-18 & 544.994 & 315.004 & 53.041 \\
S-3 & 360.051 & 262.286 & 31.894 & S-19 & 139.683 & 68.264 & 37.565 \\
S-4 & 363.194 & 247.538 & 33.351 & S-20 & 146.486 & 74.237 & 21.280 \\
S-5 & 98.124 & 67.293 & 7.072 & S-21 & 176.729 & 54.473 & 45.275 \\
S-6 & 208.306 & 124.570 & 10.029 & S-22 & 406.144 & 145.703 & 5.811 \\
S-7 & 139.457 & 19.346 & 13.241 & S-23 & 164.914 & 93.037 & 29.277 \\
S-8 & 316.360 & 221.135 & 25.875 & S-24 & 239.624 & 32.030 & 147.321 \\
S-9 & 182.071 & 74.672 & 19.242 & S-25 & 132.856 & 17.117 & 87.373 \\
S-10 & 71.845 & 12.486 & 7.186 & S-26 & 169.974 & 72.700 & 67.186 \\
S-11 & 111.109 & 45.638 & 9.341 & S-27 & 66.316 & 41.683 & 7.680 \\
S-12 & 101.271 & 36.943 & 8.692 & $\mathrm{~d}_{1}{ }^{-}$ & - & - & - \\
S-13 & 96.699 & 65.984 & 7.451 & $\mathrm{~d}_{2}{ }^{-}$ & - & - & - \\
S-14 & 1.421 .624 & 1.152 .962 & 45.143 & $\mathrm{~d}_{1}{ }^{+}$ & - & - & - \\
S-15 & 95.967 & 60.612 & 5.643 & $\mathrm{~d}_{2}{ }^{+}$ & - & - & - \\
S-16 & 402.137 & 176.843 & 62.015 & & & & \\
\hline
\end{tabular}

Tablo 5 dikkate alındığında 2019 y1lı için belirlenen $\mathrm{Z}_{\mathrm{iş}}=978.223 .659$ (bin) $\mathrm{TL}$ ve $\mathrm{Z}_{\mathrm{GSYH}}=4.450 .278 .000$ (bin) TL hedefler için sektörel üretimler bulunmuştur. Belirlenen hedefler için herhangi bir sapmanın yer almadığ görülmektedir. Sektörel bazda inceleme yapıldığında 2019 yılında toplam arz içerisinde en yoğun ilk üç sektör sırasıyla Sektör-1: Tarım, Sektör-14: Elektrik ve iklimlendirme ve Sektör-18: Taşıma, posta ve kurye hizmetleri olarak belirlenmiştir. 2020 hedefleri için elde edilen sonuçlar Tablo 6'da gösterilmiştir. 
Tablo 6

2020 Hedef Programlama Sektörel Üretim, GSYH ve İsgücü Ödeme Değerleri (Milyon TL)

\begin{tabular}{llllllll}
\hline Sektör & Üretim & GSYH & İgücü & Sektör & Üretim & GSYH & İģücü \\
\hline S-1 & 1.049 .373 & 449.253 & 27.123 & S-17 & 472.064 & 136.421 & 128.361 \\
S-2 & 487.299 & 172.889 & 21.137 & S-18 & 541.483 & 312.975 & 52.700 \\
S-3 & 338.158 & 246.338 & 29.954 & S-19 & 141.353 & 69.081 & 38.014 \\
S-4 & 304.203 & 207.332 & 27.934 & S-20 & 153.885 & 77.986 & 22.355 \\
S-5 & 96.391 & 66.104 & 6.947 & S-21 & 209.809 & 64.669 & 53.750 \\
S-6 & 197.654 & 118.200 & 9.517 & S-22 & 328.544 & 117.864 & 4.701 \\
S-7 & 118.045 & 16.375 & 11.208 & S-23 & 170.395 & 96.130 & 30.250 \\
S-8 & 294.453 & 205.822 & 24.083 & S-24 & 242.822 & 32.457 & 149.287 \\
S-9 & 182.351 & 74.787 & 19.271 & S-25 & 133.675 & 17.223 & 87.912 \\
S-10 & 73.210 & 12.724 & 7.322 & S-26 & 170.207 & 72.800 & 67.278 \\
S-11 & 111.586 & 45.833 & 9.381 & S-27 & 66.429 & 41.754 & 7.693 \\
S-12 & 101.203 & 36.918 & 8.686 & $\mathrm{~d}_{1}{ }^{-}$ & - & - & - \\
S-13 & 91.055 & 62.133 & 7.016 & $\mathrm{~d}_{2}{ }^{-}$ & - & - & - \\
S-14 & 2.666 .269 & 2.162 .390 & 84.666 & $\mathrm{~d}_{1}{ }^{+}$ & - & - & - \\
S-15 & 89.123 & 56.290 & 5.241 & $\mathrm{~d}_{2}{ }^{+}$ & - & - & - \\
S-16 & 402.048 & 176.804 & 62.002 & & & & \\
\hline
\end{tabular}

Tablo 6 dikkate alındığında 2020 yılı için belirlenen $Z_{\text {iş }}=1.003 .791 .326$ (bin) $T L$ ve $\mathrm{Z}_{\mathrm{GSYH}}=5.149 .551 .000$ (bin) TL hedefler için sektörel üretimler bulunmuştur. Elde edilen sonuçlar için 2020 yılı hedeflerinde herhangi bir sapmanın yer almadığı görülmektedir. Sektörel bazda inceleme yapıldığında 2020 yılında toplam arz içerisinde en yoğun ilk üç sektör sırasıyla Sektör-14: Elektrik ve iklimlendirme, Sektör-1: Tarım ve Sektör-18: Taşıma, posta ve kurye hizmetleri olarak belirlenmiştir. 2021 hedefleri için elde edilen sonuçlar Tablo 7'de gösterilmiştir.

Tablo 7

2021 Hedef Programlama Sektörel Üretim, GSYH ve İsgücü Ödeme Değerleri (Milyon TL)

\begin{tabular}{|c|c|c|c|c|c|c|c|}
\hline Sektör & Üretim & GSYH & İşgücü & Sektör & Üretim & GSYH & İşgücü \\
\hline S-1 & 289.976 & 124.143 & 7.495 & S-17 & 446.249 & 128.960 & 121.342 \\
\hline$S-2$ & 648.189 & 229.971 & 28.115 & S-18 & 528.996 & 305.757 & 51.484 \\
\hline$S-3$ & 311.045 & 226.587 & 27.553 & S-19 & 142.557 & 69.669 & 38.338 \\
\hline S-4 & 262.138 & 178.662 & 24.072 & $S-20$ & 160.293 & 81.234 & 23.286 \\
\hline S-5 & 93.778 & 64.312 & 6.759 & $S-21$ & 243.328 & 75.001 & 62.337 \\
\hline S-6 & 179.075 & 107.090 & 8.622 & $S-22$ & 329.312 & 118.140 & 4.712 \\
\hline S-7 & 153.102 & 21.238 & 14.537 & $S-23$ & 174.450 & 98.417 & 30.970 \\
\hline$S-8$ & 195.088 & 136.366 & 15.956 & S-24 & 246.676 & 32.972 & 151.657 \\
\hline S-9 & 182.803 & 74.972 & 19.319 & S-25 & 134.412 & 17.317 & 88.397 \\
\hline S-10 & 74.750 & 12.991 & 7.476 & S-26 & 170.013 & 72.717 & 67.201 \\
\hline S-11 & 111.455 & 45.780 & 9.370 & S-27 & 66.514 & 41.807 & 7.703 \\
\hline$S-12$ & 101.114 & 36.886 & 8.679 & $\mathrm{~d}_{1}^{-}$ & - & - & - \\
\hline S-13 & 90.772 & 61.939 & 6.995 & $\mathrm{~d}_{2}^{-}$ & - & - & 17.245 \\
\hline S-14 & 3.883 .945 & 3.149 .947 & 123.333 & $\mathrm{~d}_{1}^{+}$ & - & - & - \\
\hline$S-15$ & 82.886 & 52.351 & 4.874 & $\mathrm{~d}_{2}{ }^{+}$ & - & - & - \\
\hline S-16 & 402.576 & 177.036 & 62.083 & & & & \\
\hline
\end{tabular}


Tablo 7 incelendiğinde 2021 y1lı için belirlenen $Z_{\text {iş }}=1.039 .908 .596$ (bin) $T L$ ve $\mathrm{Z}_{\mathrm{GSYH}}=5.742 .264 .000$ (bin) TL hedefler için sektörel üretimler bulunmuştur. YEP çerçevesinde elde edilen sektörel üretim değerleri tabloları incelendiğinde 2021 hedeflerinin gerçekleşmesinde istihdam ödemelerinde 17.245.127 (Bin) TL negatif yönlü sapma bulunmaktadır. 2016 girdi çıktı tablosu koşulları geçerli olduğu varsayılırsa 2021 istihdam hedeflerine \%1,69 oranında ulaşılamayacağı söylenebilir. Sektörel bazda inceleme yapıldığında 2021 yılında toplam arz içerisinde en yoğun ilk üç sektör sırasıyla Sektör-14: Elektrik ve iklimlendirme, Sektör-2: Maden ve Sektör-18: Taşıma, posta ve kurye hizmetleri olarak belirlenmiştir. 2016 yılı tablosu baz alındığıda YEP hedeflerinin gerçekleşmesi için gereken toplam arz ve GSYH artışları Tablo 8'de verilmiştir.

Tablo 8

YEP Hedefleri Çerçevesinde Toplam Arz ve GSYH (Bin TL)

\begin{tabular}{lllll}
\hline Y1llar & Arz & Artış & GSYH & Artı̧̧ \\
\hline 2016 & 5.555 .655 .570 & - & 2.608 .525 .749 & - \\
2019 & 8.630 .119 .924 & $55,34 \%$ & 4.450 .278 .000 & $70,61 \%$ \\
2020 & 9.233 .088 .385 & $6,99 \%$ & 5.149 .551 .000 & $15,71 \%$ \\
2021 & 9.705 .493 .640 & $5,12 \%$ & 5.742 .264 .000 & $11,51 \%$ \\
\hline
\end{tabular}

\section{Sonuç, Tartışma ve Öneriler}

Girdi çıktı analizinin hedef programlama ile uygulama örneği olarak orta vadeli programlar çerçevesinde incelemeler yapılmıştır. Kalkınma bakanlığı tarafından yayınlanan YEP programında yer alan GSYH ve istihdam hedefleri dikkate alınarak hedeflerin gerçekleşmesi için gereken sektörel üretim değerleri aranmıştır. Çözümlemelerde GSYH ve istihdam hedefleri eşit ağırlıklı olarak belirlenerek çözümler elde edilmiştir. YEP programının gerçekleşmesi için elde edilen sektörel üretimler toplam arz içerisindeki yoğunluk ve üretim artışları olarak ilgili yıllar için incelenmiştir.

Güncelleme sonrası elde edilen 2016 yılı girdi çıktı tablosu için toplam arz içerisinde yoğunluğu en fazla olan sektörler sirasıyla Sektör-16: İnşaat, Sektör-3: Yiyecek, içecek ve tütün ile Sektör-22: Gayrimenkul hizmetleri şeklindedir. YEP programı çerçevesinde 2019 yılı toplam arz içerisinde yoğunluk sırası Sektör-1: Tarım, Sektör-14: Elektrik ve iklimlendirme ve Sektör-18: Taşıma, posta ve kurye şeklinde değişmiştir. 2016 yılı içerisinde bulunan inşaat ve gayrimenkul sektörleri yerine tarım, enerji ve taşıma sektörlerinin ön plana çıtığı görülmektedir. 2020 yılı için sektörler aynı olmasıyla birlikte yoğunluk sıralamasında Sektör-14: Elektrik ve iklimlendirme, Sektör1: Tarım sektörünün önüne geçerek enerji sektörü yoğunluğunu arttırmıştır. 2021 yılında ise Sektör-1: Tarım sektörü yerine ikinci sırada Sektör-2: Maden yer almıştır. YEP çerçevesinde sektörel yoğunlukların enerji, tarım, taşıma ve maden sektörlerinde artış gösterdiği belirlenmiştir.

YEP yer alan 2019, 2020 ve 2021 y1lı hedeflerinin gerçekleşmesi için toplam arzda \%24,53 artış olması beklenmektedir. Yıllar itibariyle sektörel bazda üretim artışları incelendiğinde ise 2019 için Sektör-1: Tarım, Sektör-2: Maden, Sektör-14: Elektrik ve iklimlendirme; 2020 yılı için Sektör-1: Tarım, Sektör-2: Maden ve Sektör-14: Elektrik ve iklimlendime; 2021 yılı için Sektör-2: Maden ve Sektör-14: Elektrik ve iklimlendimede artış oranlarının daha fazla olduğu görülmektedir. YEP programı çerçevesinde sektörel üretim artış oranları enerji, maden ve tarım sektörlerinde daha fazla olduğu görülmüştür.

Elden edilen sonuçlar çerçevesinde yoğunluk ve üretim artış oranlarında Türkiye'de enerji, maden ve tarım sektörleri öne çıkmaktadır. Türkiye'nin Doğu Akdeniz ve Karadeniz başta olmak üzere enerji ve maden sektörlerinde devam eden araştırma ve yatırımların yerinde ve kritik öneme sahip olduğu görülebilmektedir. Tarım sektöründe ise artan nüfus, iklimsel bozulma ve su kıtlığı karşısında yüksek verim elde etmek için modern tarım uygulamaları ihtiyaç olmaktan çıkıp zorunluluk haline gelmiştir. Genel olarak öne çıkan sektörlerin Türkiye için ekonomik önemi oldukça fazladır. 
Girdi çıktı tablolarının elde edilmesi uzun zaman ve emek isteyen bir süreçtir. Bu tablolar ile ekonomiyi yakından ilgilendiren gelir, istihdam vb. konularda çoğaltan analizleri yapılabilmektedir. Ayrıca sonuçların uygulanabilirliğini arttırmak için girdi çıktı tabloları RAS yöntemi gibi istatiksel yöntemeler ile güncellenebilmektedir. Bu uygulamalar yardımıyla sonraki çalışmalarda kısa, orta ve uzun vade ekonomik programları değerlendirilebilir. Programlarda yer alan ekonomik hedeflerin gerçekleştirilmesi için sektörel üretim değerleri bulunabilir. Böylece sektörel anlamda yatırımların yönlendirilmesi ve teşvik gibi konularda karar vericilere yol göstermiş olacaktır.

Açıklama: Bu çalışma Prof. Dr. Hüdaverdi BİRCAN danışmanlığında hazırlanan "Bulanık Girdi Çıktı Analizi ile Doğrusal ve Hedef Programlama: Türkiye Örneği” adlı doktora tezinden üretilmiştir

\section{Kaynaklar}

Apaydın A. ve Dalkılıç F. (2001). Girdi çıktı analizi ve hedef programlama, 2. İstatistik Kongresi Bildiriler Kitabl, Antalya, s.70-73.

Aydoğuş, O. (2010). Girdi-çıktı modellerine giriş. Ankara: Efil Yayınevi.

Aydoğuş, O. (2012). İzmir bölgesi girdi-çıktı analizi. İzmir: İzmir Kalkınma Ajansı (İZKA).

Bui T. and Nguyen V. P. (2013). A short note on ras method, Advances in Management \& Applied Economics, vol. 3, no.4, 2013, 133-13.

Can, T. and Ozluer, B. (2012). Input-output analysis with linear programming: The case of Turkey. International Research Journal of Finance and Economics, (89), 138-145.

Çoban, M. N. (2020). Ekonomik kompleksite ve insani gelişmişlik ilişkisi: E7 ülkeleri için bir analiz. Ahi Evran Üniversitesi Sosyal Bilimler Enstitüsü Dergisi, 6(2), 467-479.

Dalkılıç, F. (1999). Girdi-çıktı analizi ve hedef programlama. Yüksek Lisans Tezi, İstatistik Bilim Dalı, Fen Bilimleri Enstitüsü, Ankara Üniversitesi, Ankara.

Gözen, M. (2019). Şirket değerlemesine kuramsal açıdan genel bir bakış. Ahi Evran Üniversitesi Sosyal Bilimler Enstitüsü Dergisi, 5(2), 198-219.

Karkacier, O. (2001). Tokat ili tarıma dayalı sanayi sektörlerinin yapısal analizi. Tokat: Ziraat Fakültesi Yayınları.

Kondo, Y. and Nakamura, S. (2005). Waste input-output linear programming model with its application to eco-efficiency analysis. Economic Systems Research, 17(4), 393-408.

Konstantinos, P. S. (2005). Goal programming input output analysis in forest management. Review of Economic Sciences, 8, 3-34.

Leontief, W. (2008). Input-output analysis. United Kingdom: Palgrave Macmillan

Makarkına, G. V. and Merkulova, T. V. (2011). Using input-output model with fuzzy parameters for analysis of sectoral structure of Ukrainian industrial region. Формування ринкової економіки в Україні, 25, 242-247.

Oliveira, C., Coelho, D. and Antunes, C. H. (2014). Coupling input-output analysis with multiobjective linear programming models for the study of economy-energy-environmentsocial (E3S) trade-offs: a review. Annals of Operations Research, 247(2), 471-502.

Özkan, M. (2003). Bulanık Hedef Programlama. Bursa: Ekin Kitabevi. 
Özlüer, B. (2011). Sektörler arası iliş̧kilerin doğrusal programlama ile analizi: Türkiye örneği. Yüksek Lisans Tezi, İstatistik Bilim Dalı, Fen Bilimleri Enstitüsü, Mimar Sinan Güzel Sanatlar Üniversitesi, İstanbul.

Öztürk, A. (1986). Leontief modeli ve doğrusal programlama. Bursa: Örnek Kitabevi.

Ribeiro Luiz Carlos De S., Kênia Barreiro De S. and Fernando Salgueiro P. (2016). An input-output linear programming model to assess Brazilian greenhouse gas emissions. Anais do XLIII Encontro Nacional de Economia [Proceedings of the 43rd Brazilian Economics Meeting]. No. 187.

Sel, A. (2019). Girdi çıktı analizi ile bulanık hedef programlama: Sektörel üretim ve elektrik tüketim değerleri projeksiyonu. Sosyal Bilimler Araştırmaları Dergisi, 267-284.

Türkiye İhracatçılar Meclisi. (2019). İhracat rakamları. 03/03/2016 tarihinde http://www.tim.org.tr adresinden erişilmiştir.

Türkiye İstatistik Kurumu. (2019). Dış ticaret istatistikleri. 30/08/2016 tarihinde http://www.tüik.gov.tr adresinden erişilmiştir.

Türkiye İstatistik Kurumu. (2019). İllere ve cinsiyete göre temel işgücü istatistikleri. 19/05/2016 tarihinde http://www.tüik.gov.tr adresinden erişilmiştir.

Türkiye İstatistik Kurumu. (2019). İllere, belde ve köylere göre genel nüfus dağılımları. 23/04/2016 tarihinde http://www.tüik.gov.tr adresinden erişilmiştir.

Türkiye İstatistik Kurumu. (2019). İllere, cinsiyete ve eğitim durumuna göre nüfus dağılımları. 29/10/2016 tarihinde http://www.tüik.gov.tr adresinden erişilmiştir.

Türkiye İstatistik Kurumu. (2019). İşü̈cü istatistikleri. 12/01/2016 tarihinde http://www.tüik.gov.tr adresinden erişilmiştir.

Türkiye İstatistik Kurumu. (2019). İstihdam edilenlerin y1llara göre iktisadi faaliyet kollar1 ve dağılımı. 13/03/2016 tarihinde http://www.tüik.gov.tr adresinden erişilmiştir.

Türkiye İstatistik Kurumu. (2019). Ulusal hesaplar, girdi çıktı tabloları. 03/04/2016 tarihinde http://www.tüik.gov.tr adresinden erişilmiştir.

Türkiye İstatistik Kurumu, (2019). Yaş grubu ve cinsiyete göre nüfus ve projeksiyonları. http://www.tüik.gov.tr adresinden 12/01/2016 tarihinde erişilmiştir

Yu, K. D. S., Aviso, K. B., Promentilla, M. A. B., Santos, J. R. and Tan, R. R. (2016). A weighted fuzzy linear programming model in economic input-output analysis: an application to risk management of energy system disruptions. Environment Systems and Decisions, 36(2), 183 195. 


\section{Extended Abstract}

\section{Introduction}

The input-output models were first examined by the structural analysis of the American economy. It was created by Wassily W. Leontief in the 1930s. In this study, Professor emphasized on closed models. Wassily W. Leontief expanded its field of application by publishing static and open models in 1951. The input-output models obtained by examining the economic data of a certain year have found a more effective place in practice with the help of sectoral connection effects, key sectors and duplicate analysis.

\footnotetext{
"The policies implemented by the countries in the path of development in parallel with their development goals should be in a way to ensure economic structure change. Turkey is undergoing rapid structural change with the industrialization cases it is a fact. Depending on the concept of a broad economic structure, approaches to explaining the structural change in the economy can yield interesting results. From these approaches, the input-output model has received wide acceptance and an important role. The input-output model has a wide range of applications with its success in explaining the relationships (relations) between both the industrial structure and the economic mechanism elements that are out of this structure and the model" (Karkacier, 2001, p. 1).
}

"Input-output models can be said as a special version of the linear programming model. Especially in event planning, input-output models can be expressed as optimization models" (Aydoğuş, 2010, p. 6). Within the framework of linear programming, maximization and minimization models can be established as well as linear programming models can be designed within the framework of specified goals.

Declared by the Ministry of Rural Development programs in Turkey, determined by economic objectives are shared with the public. In the study, the targets in the New Economy Program (YEP) were examined. Analyzes were made by taking into account the Gross Domestic Product (GDP) and employment targets determined in the program. Taking into consideration the YEP, the years 2019, 2020 and 2021 were examined and the YEP targets were evaluated on the most recently calculated 2016 input-output table. In order to keep the study results up-to-date and feasible, the most recently published input-output table was used. Firstly, the 64-sector 2012 input-output table was reduced to 27 sectors with the help of consolidation. Then, the input-output table for 2012 was updated to 2014 with the RAS method and to 2016 with the current table of 2014.

\section{Method}

In the goal programming model, studies can be performed on a target or operations can be performed within more than one target framework. When the GDP target, which examines the basic dynamics of the economy, is defined as " $Z_{G S Y H}$ " and the employment target as " $Z_{i s}$ ", the model can be regulated as Equation 1 for values that minimize deviations from the target under the constraints of supply-demand, fixed capital use and labor force.

$$
\begin{aligned}
& \min =d_{1}^{-}+d_{1}^{+}+d_{2}^{-}+d_{2}^{+} \\
& Z_{i S}=\sum_{j=1}^{n} l_{j} X_{j}+d_{1}^{-}-d_{1}^{+} \\
& Z_{G S Y H}=\sum_{j=1}^{n} g_{j} X_{j}+d_{2}^{-}-d_{2}^{+} \\
& \sum_{j=1}^{n}\left(1-a_{i j}\right) X_{j} \geq Y_{i}
\end{aligned}
$$




$$
\begin{aligned}
& \sum_{j=1}^{n} l_{j} X_{j} \geq L \\
& \sum_{j=1}^{n} k_{j} X_{j} \leq K \\
& X_{j} \geq 0
\end{aligned}
$$

The explanations of the expressions in Equation 1 are as follows.

$X_{j}$ : Production level in sector $\mathrm{j}$

$a_{i j}$ : Amount of goods required by sector $\mathrm{j}$ to produce one unit of goods

$Y_{i}$ : Total final consumption expenditure of the i sector

$l_{j}$ : The amount of labor required by the $\mathrm{j}$ sector to produce one unit of goods

$g_{j}$ : The amount of GDP needed by the $\mathrm{j}$ sector to produce one unit of goods

$L$ : Current labor force in the economy

$k_{j}$ : The amount of capital required for sector $\mathrm{j}$ to produce one unit of goods

$K$ : The amount of available capital in the economy

$d_{l}{ }^{-}$: Negative deviation value for employment target

$\mathrm{d}_{l}^{+}$: Positive deviation value for employment target

$d_{2}{ }^{-}$: Negative deviation value for GDP target

$d_{2}{ }^{+}$: Positive deviation value for GDP target

No priority has been set for the objectives during the implementation. GDP and employment targets were evaluated equally and solutions were made. Target years given in YEP include the years 2019-2020 and 2021. The last updated table created for the input and output tables belongs to 2016 . Considering this table, the production values that will meet the GDP and employment targets in the BRP are calculated. The most recent Turkish Statistical Institute data published in the year of the study for employment targets is in 2017. Here, employment payment is 947.078 .813 (thousand) TL for 28.189 (thousand) people. The payment amounts for the years 2019-2020-2021 have been set as targets. The constraints from $\mathrm{C} 1$ to $\mathrm{C} 27$, the constraints used in the study, are the Ci's, the supply demand constraints in Equation 1. The values $\left(1-a_{i j}\right)$ on the left side of the supply demand constraints calculated on the 2016 input-output table represent the Leontief matrix.

Since the 2016 input-output table is used in the restrictions applied for the target years, the labor low limit and capital upper limit are the values obtained from this table. C28 constraint capital usage upper limit $(\mathrm{K})$ is determined as $\mathrm{C} 28 \leq 50.363 .004$ (Thousand TL). The lower limit (C) of payments made to the C29 constraint employees is determined as C29 $\geq 840.205 .090$ (Thousand TL). Employment "Payment" and "GDP" amounts for 2019, 2020 and 2021 are targets; target labor payment amount $\left(Z_{i s}\right)$ and target gross domestic product value are defined as " $Z_{G S Y H}$ ".

\section{Result, Discussion and Conlusion}

It is expected that there will be a $24.53 \%$ increase in total supply in order to achieve the 2019 , 2020 and 2021 targets included in the YEP. The common sectors, which have a high production increase in achieving this goal, have been determined over the relevant years. Sector-1: Agriculture, Sector-2: Mining, Sector-14: Electricity and air conditioning to achieve the 2019 target within the framework of the YEP targets; Sector-1: Agriculture, Sector-2: Mining and Sector-14: Electricity and air conditioning to achieve the target of 2020; In order to achieve the 2021 target, Sector-2: Mining and Sector-14: It is observed that production increase rates are higher in electricity and air conditioning. With the investments made in these sectors, the 2019, 2020 and 2021 targets are more likely to be achieved within the framework of the YEP.

Obtaining input and output tables is a long and labor-intensive process. With these tables, the duplicate analysis that closely concerns the economy is made and income, employment, etc. issues can 
be investigated. In addition, input and output tables can be updated with the RAS method to increase the applicability of the results. Short, medium and long term economic programs can be evaluated thanks to the model established. Thus, sectoral comments can be developed in order to direct investments for decision makers on the economy. 